\title{
Who Enrolls in Head Start? A Demographic Analysis of Head Start-Eligible Children
}

\author{
Sandra L. Hofferth \\ University of Michigan
}

This article describes those who were and were not served by Head Start in 1990, and draws implications for program expansion. We first examined how characteristics of the child, the family, and the community were associated with the enrollment of poor 3- to 5-year-old children in Head Start. Second, we identified the types of programs and child-care arrangements in which non-Head Start children were enrolled in 1990. Third, we looked at how family and community characteristics are related to Head Start-eligible parents' use of multiple arrangements. Finally, we explored the types of supplementary and "wraparound" arrangements Head Start and non-Head Start children use.

The sample was taken from the National Child Care Survey 1990. It consisted of 212 children ages 3 to 5 who, in 1990, were living with their mother, were not enrolled in school, and whose families were poor or on Aid to Families with Dependent Children (AFDC). Results suggest that, in 1990, family structure was related to enrollment in Head Start; children in twoparent families with no earners were the most likely to be enrolled. In contrast to what was expected, there was little difference in enrollment by employment status of the mother per se, though having a mother in a job training program was associated with greater enrollment. Black children were more likely to be enrolled than children from other race/ethnic groups. Of 3- to 5-year-olds not enrolled in Head Start, only about one quarter were enrolled in a center-based program, and only about half of these were in programs offering comprehensive services. The majority of children not enrolled in Head Start were in parent or in relative care. Thus there appears to be substantial room to expand the Head Start program without pulling children out of comparable existing programs.

This research was funded with a grant from the Pew Charitable Trusts. The editorial assistance of Kyna Rubin and the research assistance of Rosalind Berkowitz are greatly appreciated.

Correspondence and requests for reprints should be sent to Sandra L. Hofferth, Institute for Social Research, University of Michigan, P.O. Box 1248, Ann Arbor, MI 48106. 


\section{INTRODUCTION}

The well-being of young children from low-income families is of special concern to policymakers, educators, and child advocates. In 1992, one quarter of 3- to 4-year-old children were living in poverty (U.S. Bureau of the Census, 1994). Federal policies such as the Family Support Act of 1988 are aimed at assisting families to become self-sufficient through a combination of employment and training programs. Most such families are headed by a single mother (Committee on Ways and Means, 1994). The availability, affordability, and quality of child care are critical to these families' ability to find and sustain employment.

Federal policies have also been aimed at directly improving the long-term well-being of low-income children through compensatory education. Providing low-income children with high-quality preschool education programs and comprehensive social services has become widely accepted as a means to improve their preparation for school, an important foundation for later success (Copple, Deich, Brush, \& Hofferth, 1993). Head Start, the foremost early childhood program for low-income children and their families, provides a wide range of services, including education, structured opportunities for parent involvement, social services, and health (Zigler, Piotrkowski, \& Collins, 1994).

An important policy goal is to facilitate the linkage between the care and education of young children whose family incomes are low (Advisory Committee on Head Start Quality and Expansion, 1993). In order to address this issue we need to understand what leads parents to enroll their children in an early childhood program such as Head Start, rather than in something else or in no program at all. What constraints do families face in enrolling their children in Head Start? Which types of families are more likely than others to enroll their children?

Head Start is mandated to serve the most needy; consequently, only the poorest may be enrolled (National Head Start Association, 1990). Because single mothers, teen mothers, those with large families, and those with limited schooling are the poorest and most at risk (Collins, 1993), their children may be more likely to be enrolled. Because of Head Start's origins during the War on Poverty, when the main minority group at risk was Black, Head Start programs may be more accessible to Black families (Zigler \& Muenchow, 1992). Mothers who are better educated or who are enrolled in governmentsponsored job training programs may receive more information and be more motivated to enroll their children.

On the other hand, employed parents may be discouraged from enrolling in Head Start because most of the existing programs operate only part day (National Head Start Association, 1990). Fewer than 15\% of Head Start programs are full day and, of those, many do not meet five days a week or for the entire year (National Head Start Association, 1990). Most of the new 
state-funded preschools that serve 3- to 4-year-olds also operate part day. Yet one of the objectives of the welfare reform legislation was to assure that public assistance recipients be enrolled in a program of schooling, training, or work. In fact, a 1988 study showed that $32 \%$ of Head Start parents were working full time and another $19 \%$ worked part time, had seasonal jobs, or were in school or training (National Head Start Association, 1989).

As a result of the part-time hours of operation of Head Start programs, many families may be unable to participate or must combine Head Start with other preschool programs or child-care arrangements in order to provide care for children while the mother is employed. The Head Start Silver Ribbon Panel (National Head Start Association, 1990) suggested that the lack of fulltime programs was a barrier to enrollment for families that can not arrange transportation or additional care for the remaining portion of the day.

As of 1992, Head Start served roughly $30 \%$ of all eligible 3- to 5-year-old children (Stewart, 1993). As it expands to serve more and more children, the question arises as to whether and how Head Start will have to change in order to serve the remaining families (Chafel, 1992; Rovner, 1991). If families cannot use Head Start for various reasons, such as inconvenient hours or location, expanding the program in its present form will still not ensure coverage of all children. In order to do so it may have to do a better job of fitting into existing patterns of preschool services. Thus the first objective of this analysis was to identify populations that are currently somewhat underserved, to determine where recruitment efforts could be best concentrated and to define the types of services that such populations would need. The second purpose was to identify whether populations not currently served by Head Start are currently served by other center-based programs that might provide some of the same services provided by Head Start. In that case, they would not necessarily need to be enrolled in Head Start. The third purpose was to identify the need for supplemental and wraparound care arrangements that families would need in Head Start. To do so, we needed to examine whether the current child-care and preschool needs of children who do not enroll in Head Start differ substantially from the needs of those who do.

This article identifies differences in the use of Head Start programs among eligible low-income and working-poor families with a 3-to 5-yearold child, by the employment status of the parents and other family characteristics such as race/ethnicity, family size, family type, and characteristics of the area in which the family lives. We address the following four questions:

- What are the characteristics of the child, the family, and the community that are associated with enrollment of eligible children in Head Start? 
- What child-care arrangements do non-Head Start children use?

- What family and community characteristics are associated with whether or not a Head Start-eligible family uses multiple arrangements for their child?

- What types of supplementary and "wraparound" child care arrangements do Head Start and non-Head Start families use?

\section{The Unique Elements of Head Start}

Although other types of early childhood programs also provide a variety of services, Head Start is unique. In 1991, a representative sample of Head Start and other early childhood programs were asked about the provision of a variety of health and social services (Kisker, Hofferth, Phillips, \& Farquhar, 1991). Three quarters of Head Start programs provided physical examinations for the children, $81 \%$ provided dental examinations, and $89 \%$ conducted psychological tests (Hofferth \& Kisker, in press). More than $95 \%$ of Head Start programs tested hearing, speech, vision, and level of cognitive and social devclopment. The early childhood programs that came closest to offering the same level of comprehensive services as Head Start were school based. Almost three quarters of school-based early childhood programs tested children for their level of cognitive and social development, and $85 \%$ conducted hearing, speech, and vision testing. However, only about one third actually conducted physical and dental examinations. Nonprofits sponsored by community groups and social service agencies were next in provision of services; about half of such programs tested children for cognitive and social development and for hearing, speech, and vision problems. Only a minority conducted physical and dental examinations or psychological tests. About one third of religious-sponsored nonprofits, independent nonprofits and for-profit chains tested for cognitive and social development. About half of these programs tested hearing, speech, and vision.

Parental involvement is also much less common in non-Head Start programs. For example, compared with $45 \%$ of public school programs, and about one quarter of other programs, $88 \%$ of Head Start programs have parent volunteers in the classrooms (Kisker et al., 1991). One of the biggest differences is that in $80 \%$ of Head Start programs, parents help select the staff and review the budgets. In few other center-based programs do parents participate to this extent.

\section{DATA}

The data used in this study come from the National Child Care Survey 1990 and A Profile of Child Care Settings. The National Child Care Survey 1990 provides data on the characteristics of children and their families, and on 
enrollment in Head Start and other early education and care programs. The Profile of Child Care Settings Study provides data on the availability of and services provided by the center-based programs and regulated family day care homes in each community in which these children live. A contextual data file provides information on the counties in which these children live.

\section{National Child Care Survey 1990}

The National Child Care Survey 1990 (NCCS) is a nationally representative survey of households with children under age 13. The survey was funded by the National Association for the Education of Young Children and the Administration for Children, Youth and Families (Hofferth, Brayfield, Deich, \& Holcomb, 1991) and was conducted by Abt Associates from November 1989 through May 1990. Through random digit-dial techniuqes, 4,392 households in 144 counties representative of the United States were interviewed by phone using computer-assisted telephone interviewing methods. These families had 7,575 children, of whom 1,783 were ages 3 to 5 . The overall response ratc to the survey was $57 \%$. Weights were computed that adjust for differential response rates as well as for differential coverage rates due to households without telephones (Abt Associates, 1990).

The objective of the survey was to obtain information about the characteristics of families with children under age 13 and the characteristics of the early education and care programs that their children attend. Consequently, detailed information was obtained about the child-care arrangements made by parents for each of their children. Head Start enrollment was ascertained separately from enrollment in other center-based programs such as centers, nursery schools, and before- and after-school programs for 3- to 5-yearolds. This survey represents the first attempt to obtain nationally representative data from parents on Head Start children and their families.

Consistent with definitions used by the Congressional Research Service (Stewart, 1993) for this study Head Start-eligible children were defined as those age 3, 4, or 5 who were not yet enrolled in school and who lived in a family with an income below the poverty line or in a family receiving AFDC. For this study, a sample was selected from the 1990 NCCS that consisted of all children who could be determined as meeting these eligibility criteria-a total of 224 children. The final sample consisted of 212 children age 3,4, and 5, who were living with their mother, not enrolled in school, and whose families were poor or on AFDC. ${ }^{1}$ Because most 5 -year-olds are

\footnotetext{
${ }^{1}$ Three children living with a single father and nine children not living with either parent were excluded from the analyses in this paper. They could not be included in the logistic regression because none were enrolled in Head Start programs. However, results on the entire sample using OLS regression suggest that the conclusions presented here (without these 12 children in the sample) do not differ from the conclusions drawn from a sample including these children.
} 
enrolled in school, only $12 \%$ of the sample are age 5 , while $88 \%$ of the sample are age 3 or 4 . Because approximately $10 \%$ of Head Start children can be above the income cutoff, our sample is slightly more income-restricted than the actual Head Start population. Weights were used to approximate characteristics of the population as a whole, though statistical tests were based on actual sample sizes. Of this weighted sample, 48 children were enrolled in Head Start. ${ }^{2}$

\section{A Profile of Child Care Settings}

The objective of A Profile of Child Care Setting (PCS) was to obtain national estimates of the level and characteristics of early childhood programs available for young children between 1989 and 1990 through telephone interviews with a representative sample of early education and child-care providers (Kisker et al., 1991). Both the NCCS and the PCS were conducted in the same counties at the same time. The sampling frame consisted of all regulated and nonregulated preschool programs and regulated family day care homes. Within this sampling frame, the actual number of Head Start programs, public school programs, other center-based programs, and licensed family day care homes in each county was obtained. It is this information that was used in this study to proxy the availability of these programs in each community.

A survey of providers was fielded by Mathematica Policy Research from October 1989 through February 1990. Using computer-assisted telephone interviewing methods, interviews were conducted with approximately 2,088 center directors and 583 family day care providers in 100 counties or groups of counties representative of the United States. The response rate for the PCS study were quite high. Interviews were conducted with $89 \%$ of center programs and $87 \%$ of home-based providers eligible for the study. The PCS survey obtained detailed information on general administrative characteristics, admission policies, enrollment size, fees and subsidies, staffing, curriculum and activities, health and safety, and operating experiences and expenses. This study provides information on the services children receive in each type of early childhood program.

\section{Contextual Data File}

Using a variety of sources such as the U.S. Bureau of the Census, the National Center for Health Statistics, and the Bureau of Economic Analysis, data were obtained for a number of contextual variables in each of the 144 counties in the NCCS and PCS. In this study we used data on personal income per capita within counties as a measure of living standards

${ }^{2}$ The NCCS also collected information from a supplementary sample of children from families with incomes below $\$ 15,000$, "the low income substudy" (Brayfield et al., 1993). Our analyses were replicated using this sample. The results, which are available from the author, do not differ in any substantial way from those reported here. 


\section{The Quality of Data for Low-Income Families}

Because the sample size is small, it is important to review evidence on the quality of the data on low-income children and their families. First, we checked the data to make sure they were representative of the low-income population of the United States. Although the NCCS correctly reproduces the overall incomes of households, it does not correctly reproduce the incomes of children. The NCCS estimate of the number of children in poverty $(500,000)$ is smaller than that found by others using the Current Population Survey $(800,000)$, which suggests that, without adjustment, the NCCS underestimates the number of poor children. Consequently, the sample was reweighted to adjust for the underestimate of poor children.

Second, because the NCCS data were collected by telephone, children in families without telephones were not interviewed, which might bias the sample if such children differ substantially in their early childhood program enrollment. This work suggests that the amount of bias existing is acceptably small (see Hofferth et al., 1991, Appendix B). Third, we compared NCCS and Current Population Survey estimates of Head Start coverage of lowincome children. These comparisons, which are discussed in the Appendix of this article, suggest that the NCCS estimates slightly underestimate Head Start enrollment among the eligible population.

\section{METHODS}

We first discuss the dependent variables, then the rationale for selecting our independent variables.

\section{Dependent Variables}

Parents were asked if their child were enrolled in Head Start, and the answer to this question was used to measure Head Start enrollment. In the analysis of multiple arrangements, the dependent variable was the number of nonparental arrangements, obtained from summing the number of nonparental arrangements parents reported.

\section{Independent Variables}

Among eligible children, what factors are associated with enrollment in Head Start or with the use of multiple arrangements? We expected to find significant differences in Head Start enrollment by age of child, age of mother at first birth, family size, income, education of mother, race and/or ethnicity of the family, employment and family structure, participation in a training program, metropolitan residence, region, cost of living, and availability of programs.

Mothers who were teenagers at first birth might learn about Head Start through teen-parent programs and, therefore, be more likely to enroll their children. Because of its mandate to serve the poorest Americans, the pro- 
gram may select the lowest income families among those eligible. The number of siblings might be associated with Head Start enrollment by affecting maternal labor force participation and family economic status. Even though low-income families are served, the most highly educated families-to the detriment of the least educated-might press hardest to enroll their children. Finally, controlling for the income factor, Black children may be more likely than other children to be enrolled because Head Start originated with the War on Poverty, at a time when Blacks were the main minority group at risk.

Among eligible families, the employment of family members is likely to have a very important influence on enrollment in Head Start. Because Head Start is only part day, part week, and part year, working mothers need additional child-care arrangements. Thus, families with an employed mother may be less able to participate in Head Start than families without an employed mother. Whereas this hypothesis is appropriate for single-mother families, it may not be for two-parent families. In some two-parent families, onc parcnt may be employed while the other is available for child care. Consequently, the effect of the employment of the mother on her child's enrollment in Head Start may depend on the number of parents present and the employment status of each. For example, the effect of the mother's employment should not reduce use of Head Start in two-parent families with only one employed parent. We created a set of dummy variables that indicate the number of parents and their employment status: two parents, both employed; two parents, mother employed; two parents, dad employed; two parents, neither employed; and a single-employed mother. ${ }^{3}$

In addition, we included a variable that was coded 1 if the mother was in job training. Such a family would be very likely to have a child in Head Start because of their greater knowledge about and access to services in addition to their part-time training schedule. On the other hand, greater access to child-care services directly through a training program might reduce the need for Head Start.

Area measures that might be related to the use of Head Start include metropolitan residence (central city, suburban, rural), region (South, West, Northwest, Midwest), and cost of living (per capita income in the county divided by 1000). Families in central cities and some areas of the country might have greater access to Head Start than other families. Because Head Start is targeted at low-income families, we might expect higher enrollment in inner city than in suburban neighborhoods and in low cost-of-living than in higher cost-of-living neighborhoods.

\footnotetext{
${ }^{3}$ We also examined the work schedule of the mother, part or full time. However, the difference by work hours of the mother never reached statistical significance. That specification was dropped in favor of taking into account the employment status of both parents.
} 
Finally, the availability of child-care programs in the community was expected to affect enrollment. In particular, the ratio of Head Start programs, public school programs, other center-based programs, and regulated family day care homes per 1,000 children under age 6 was expected to be associated with whether an eligible child would be enrolled in Head Start. The greater the availability of Head Start slots, the more children can be enrolled. The availability of other options competing with Head Start may reduce Head Start enrollment.

\section{RESULTS}

\section{Factors Associated with Enrollment in Head Start}

Means for all variables based on the sample of 212 children living with their mothers and eligible for Head Start are shown in Table 1. About $23 \%$ of the (weighted) samplc of eligible 3-, 4-, and 5-year-olds not enrolled in school participated in Head Start in late 1989 and early 1990. This is consistent with national estimates of coverage based on CPS data (see the Appendix).

The proportion of eligible children enrolled in Head Start for the entire sample was first examined separately by each of the independent variables listed in Table 1 (bivariate analysis). Because several of these variablessuch as education of mother, family structure, income of mother, and age at first birth-were correlated, to see which factors remain significantly associated with Head Start enrollment when others are controlled, these variables were entered simultaneously into the model. ${ }^{4}$ For the total sample of 212 children living with their mother and eligible for Head Start, logistic regression was used to analyze the relationship between each of the above factors and enrollment in Head Start, adjusting for all other factors (multivariate analysis). ${ }^{5}$

In the bivariate analyses (Table 2), we found significant differences in Head Start enrollment by age of child, age of mother at first birth, education of mother, employment and family structure, and central city versus

${ }^{4}$ In order to reduce the number of variables, age of mother at first birth and number of children, whose coefficients were small and not significant, were deleted from the multivariate model.

${ }^{3}$ Because the dependent variable is dichotomous, multiple logistic regression was used. This models the $\log$ of the odds ratio, $\ln (\mathrm{P}($ Head Start $=1) / 1-\mathrm{P}($ Head Start $=1)$, as a function of the variables described above, $b_{1} X_{i 1}+b_{2} X_{i 2}, \ldots b_{k} X_{i k}$ (Aldrich and Nelson, 1984). By taking the antilog of each coefficient $b_{k}$ we obtain the odds ratio, $(P / 1-P)$. If we subtract one from the odds ratio and multiply by 100 we obtain the percent increase (or decrease) in the adjusted odds of enrolling in Head Start associated with the category of interest relative to the comparison category. 
Table 1. Mean and Standard Deviation Scores of Variables Used in the Analyses

\begin{tabular}{lrr}
\hline Variable & Mean & Standard Deviation \\
\hline Three-years-old & .425 & .495 \\
Four-years-old & .455 & .499 \\
Five-years-old & .120 & .326 \\
Household income (in thousands) & 9.312 & 6.234 \\
Education of mother & 11.350 & 2.690 \\
Caucasian & .449 & .499 \\
African American & .303 & .461 \\
Hispanic & .227 & .420 \\
Central city & .424 & .495 \\
Suburb & .280 & .450 \\
Rural & .296 & .457 \\
Age at first birth & 21.018 & 3.986 \\
Number of childrent under 13 & 2.542 & 1.044 \\
West & .272 & .446 \\
Midwest & .227 & .420 \\
Northeast & .134 & .342 \\
South & .367 & .483 \\
Two parents, both employed & .133 & .341 \\
Two parents, mother employed & .031 & .173 \\
Two parents, father employed & .182 & .387 \\
Two parents, neither employed & .090 & .287 \\
Single nonemployed mother & .377 & .486 \\
Single employed mother & .187 & .391 \\
Mother in training & .098 & .298 \\
Per capita income in county & 14.487 & 3.908 \\
Ratio of Head Start programs per 1,000 children $<6$ & .428 & .493 \\
Ratio of centers per 1,000 children $<6$ & 3.364 & .482 \\
Ratio of family day care homes per 1,000 children $<6$ & 8.503 & 8.466 \\
Ratio of public school programs per 1,000 children $<6$ & .623 & .809 \\
Sample size & 212 & \\
\hline & & \\
\hline & & \\
& &
\end{tabular}

suburban residence. After controlling for other factors, however, multivariate results showed that age of mother at first birth, number of children, and metropolitan residence were not related to enrollment in Head Start (not shown). In contrast, age of the child, education of the mother, race, region, family structure and employment status of the parents, whether the household head was enrolled in a training program, standard of living, and supply of child-care in the county were found to be associated with enrollment in Head Start (Table 3). Detailed results follow.

Age of Child. According to our data, $11 \%$ of 3-year-olds, $33 \%$ of 4-year-olds, and $25 \%$ of 5 -year-olds not enrolled in school were enrolled in Head Start in 1990 (Table 2). In the bivariate analysis, 3-year-olds were significantly less likely to be enrolled in Head Start than 4-year-olds, with 
Table 2. Head Start Enrollment, by Characteristics of Child, Family, and Area

\begin{tabular}{|c|c|c|}
\hline Age of Child & $\begin{array}{c}\% \text { Enrolled in } \\
\text { Head Start }\end{array}$ & $\begin{array}{c}95 \% \text { Confidence } \\
\text { Interval } \\
\end{array}$ \\
\hline Age 3 & 11 & \pm 8 \\
\hline Age 4 & 33 & \pm 9 \\
\hline Age 5 & 25 & \pm 12 \\
\hline \multicolumn{3}{|l|}{ Family Structure and Employment } \\
\hline Two parents, both employed & 20 & \pm 11 \\
\hline Two parents, mother employed & 12 & \pm 8 \\
\hline Two parents, father employed & 16 & \pm 11 \\
\hline Two parents, neither employed & 52 & \pm 14 \\
\hline Single nonemployed mother & 25 & \pm 12 \\
\hline Single employed mother & 15 & \pm 10 \\
\hline \multicolumn{3}{|l|}{ Race } \\
\hline Caucasian & 13 & \pm 6 \\
\hline African American & 30 & \pm 13 \\
\hline Hispanic & 34 & \pm 13 \\
\hline \multicolumn{3}{|l|}{ Region } \\
\hline West & 27 & \pm 13 \\
\hline South & 14 & \pm 8 \\
\hline Midwest & 28 & \pm 13 \\
\hline Northeast & 27 & \pm 13 \\
\hline \multicolumn{3}{|l|}{ Urban } \\
\hline Central city & 29 & \pm 9 \\
\hline Suburban & 11 & \pm 8 \\
\hline Rural & 26 & \pm 13 \\
\hline \multicolumn{3}{|l|}{ Education of Mother } \\
\hline Less than high school & 35 & \pm 13 \\
\hline High school diploma only & 20 & \pm 8 \\
\hline More than high school & 13 & \pm 8 \\
\hline \multicolumn{3}{|l|}{ Training } \\
\hline Received training & 39 & \pm 14 \\
\hline Did not receive training & 21 & \pm 6 \\
\hline \multicolumn{3}{|l|}{ Income } \\
\hline$<\$ 5,000$ & 27 & \pm 13 \\
\hline$\$ 5,000-\$ 9,999$ & 29 & \pm 9 \\
\hline$\$ 10,000-\$ 14,999$ & 15 & \pm 7 \\
\hline$\$ 15,000+$ & 17 & \pm 10 \\
\hline \multicolumn{3}{|l|}{ Age at 1st Birth } \\
\hline$<18$ & 37 & \pm 13 \\
\hline $18-19$ & 29 & \pm 13 \\
\hline $20+$ & 16 & \pm 6 \\
\hline \multicolumn{3}{|l|}{ Number of Children } \\
\hline 1 & 15 & \pm 9 \\
\hline 2 & 27 & \pm 13 \\
\hline 3 & 25 & \pm 11 \\
\hline 4 & 21 & \pm 11 \\
\hline 5 & 11 & \pm 8 \\
\hline Sample Size & 212 & \\
\hline
\end{tabular}


Table 3. Logistic Regression of Head Start Enrollment and OLS Regression of Number of Arrangements on Child, Family, and Area Characteristics

\begin{tabular}{|c|c|c|c|}
\hline Variable & $\begin{array}{c}\text { Head Start } \\
\text { Enrollment (SE) }\end{array}$ & Odds Ratio & $\begin{array}{c}\text { Number of } \\
\text { Arrangements (SE) }\end{array}$ \\
\hline Intercept & $\begin{array}{c}-3.059+ \\
(1.799)\end{array}$ & .047 & $\begin{array}{c}766 \\
(.437)\end{array}$ \\
\hline Age three & $\begin{array}{c}-2.729 * * * \\
(.633)\end{array}$ & .065 & $\begin{aligned}-.038 \\
(.120)\end{aligned}$ \\
\hline Age four & $\mathrm{a}$ & 1.000 & $\mathrm{a}$ \\
\hline Age five & $\begin{array}{r}-.306 \\
(.643)\end{array}$ & .736 & $\begin{array}{l}.207 \\
(.172)\end{array}$ \\
\hline $\begin{array}{l}\text { Household income } \\
\text { (in thousands) }\end{array}$ & -.058 & .944 & -.008 \\
\hline Education of mother & $\begin{array}{l}.224^{*} \\
(.095)\end{array}$ & .799 & $\begin{array}{r}.037 \\
(.023)\end{array}$ \\
\hline African American & $\begin{array}{l}2.473^{* * *} \\
(.638)\end{array}$ & 11.860 & $\begin{array}{l}.056 \\
(.140)\end{array}$ \\
\hline Hispanic & $\begin{array}{l}.045 \\
(.776)\end{array}$ & 1.046 & -.011 \\
\hline Caucasian & $\mathrm{a}$ & 1.000 & $\mathbf{a}$ \\
\hline South & $\begin{array}{l}-2.095^{* *} \\
(.691)\end{array}$ & .123 & $\begin{array}{r}-.104 \\
(.151)\end{array}$ \\
\hline Northeast, midwest, west & $\mathrm{a}$ & 1.000 & $a$ \\
\hline Two parents, both employed & $\begin{array}{c}.967 \\
(.850)\end{array}$ & 2.631 & $\begin{array}{r}-.400^{*} \\
(.196)\end{array}$ \\
\hline Two parents, mother employed & $\begin{array}{r}-.542 \\
(1.625)\end{array}$ & .582 & $\begin{array}{r}-.297 \\
(.338)\end{array}$ \\
\hline Two parents, father employed & $\begin{array}{l}.157 \\
(.797)\end{array}$ & 1.170 & $\begin{array}{l}-.898^{* * * *} \\
(.178)\end{array}$ \\
\hline Two parents, neither employed & $\begin{array}{l}2.311^{* *} \\
(.897)\end{array}$ & 10.083 & $\begin{array}{c}-1.018^{* * * *} \\
(.226)\end{array}$ \\
\hline Single non-employed mother & $\begin{array}{l}.468 \\
(.681)\end{array}$ & 1.597 & $\begin{array}{l}-.850^{* * *} \\
(.157)\end{array}$ \\
\hline Single employed mother & $\mathrm{a}$ & 1.000 & $\mathrm{a}$ \\
\hline Mother in job training program & $\begin{array}{l}2.407^{* * *} \\
(.795)\end{array}$ & 11.096 & $\begin{array}{l}.442^{*} \\
(.197)\end{array}$ \\
\hline Per capita income in county & $\begin{array}{l}.178^{* *} \\
(.069)\end{array}$ & 1.194 & $\begin{array}{l}.016 \\
(.017)\end{array}$ \\
\hline Head Start $/ 1,000$ kids $<6$ & $\begin{array}{l}1.850+ \\
(1.010)\end{array}$ & 6.358 & $\begin{array}{l}.377+ \\
(.212)\end{array}$ \\
\hline Centers $/ 1,000$ kids $<6$ & $\begin{array}{l}.548^{* *} \\
(.201)\end{array}$ & 1.729 & $\begin{array}{l}.081+ \\
(.047)\end{array}$ \\
\hline Family Day Care $/ 1,000$ kids $<6$ & $\begin{array}{c}-.075+ \\
(.045)\end{array}$ & .928 & $\begin{array}{c}.002 \\
(.010)\end{array}$ \\
\hline $\begin{array}{l}\text { Public school programs/ } \\
1,000 \text { kids }<6\end{array}$ & $\begin{array}{r}-.197 \\
(.610)\end{array}$ & .821 & $\begin{aligned}-.158 \\
(.131)\end{aligned}$ \\
\hline Number of children & - & - & $-.120^{*}$ \\
\hline Enrolled in Head Start & - & - & $\begin{array}{l}.720^{* * *} \\
(.150)\end{array}$ \\
\hline-2 log likelihood & $83.363 * * *$ & & NA \\
\hline Df & 18 & & 20 \\
\hline$R^{2}$ & NA & & $.372 * * *$ \\
\hline$N$ & 212 & & 212 \\
\hline
\end{tabular}

$* p<.05 . \quad * * p<.01 \quad * * * p<.001$.

Note. The following symbols have been used in this table: a the comparison category;

- not included in the regression; na not applicable; $+p<.10$. 
no difference between 4- and 5-year-olds. In the multivariate analysis, controlling for other factors, 3-year-olds were also significantly less likely than 4-year-olds (the comparison category) to be enrolled in Head Start (Table 3). There is no statistically significant difference between the enrollment of 4- and 5-year-olds, controlling for other factors.

Age of Mother at First Birth. As shown in Table 2, 37\% of children of mothers who were under 18 at first birth were enrolled in Head Start in 1990 , compared with $29 \%$ of children of mothers who were age 18 to 19 and $16 \%$ of children of mothers who were age 20 or older at first birth. The enrollment of children of mothers who were under 18 at first birth was statistically significant. However, once other factors are controlled, we find no evidence that children of mothers who had their first birth at a young age were more likely than children of older mothers to be enrolled in Head Start (not shown).

Number of Children. As seen in Table 2, children in one-child families were less likely to be enrolled in Head Start in 1990 than those in two-child families $(\mathbf{2 7 \%})$, though the difference was not statistically significant. Controlling for other factors, however, children in small families were no less likely than children in large families to be enrolled in Head Start (not shown).

Family Structure and Employment. Children living with two parents, neither of whom is employed, were the most likely to be enrolled in Head Start in 1990. As illustrated in Table 2, 52\% of children living in a twoparent no-earner family were enrolled in Head Start in 1990, compared with $25 \%$ of children living in a single nonemployed mother family, $20 \%$ of children in dual-earner families, $15 \%$ of children in single-employedmother families, and 12 to $16 \%$ of children in two-parent single-earner families.

In the multivariate analysis, single-employed mothers constituted the comparison category. Net of other factors, children in two-parent no-earner families were significantly more likely than those living with a singleemployed mother to be enrolled in Head Start (Table 3). No significant difference between the enrollment of children in employed and nonemployed single-mother families was found. Thus, the data only partially support our conjecture that Head Start serves a larger proportion of nonemployed than employed parent families. The data support this hypothesis for two-parent nonemployed families but not for single-parent nonemployed families.

The number of parents in a family is important, however. The presence of two parents greatly improves enrollment in Head Start. Controlling for other factors, children of dual-earner couples have a slightly (but not significantly) higher enrollment than children of employed single mothers (Table 3 ). The only group with lower enrollment than children of employed 
single mothers are children in two-parent employed-mother families (thought the coefficient is not statistically significant).

We can speculate on the reasons why children in two-parent families show such a high enrollment. The presence of two parents makes the care of children much easier. It permits sharing child-care, including pickup and drop-off at a program and care for the child before or after the program. It facilitates involvement and participation in parent councils and other Head Start activities. Single mothers may find it too difficult to participate in Head Start. An alternative explanation is that factors that led to the formation of a single-parent family in the first place also prevent enrollment of children in Head Start. There is apparently substantial room for improvement in the Head Start enrollment of eligible children of single parents.

The results suggest that addressing the employment- and child-carerelated needs of employed single-mother families and two-parent one- or two-earner families might increase enrollments. There are a large number of such families, relative to nonemployed two-parent families, with children eligible for but not currently enrolled in Head Start.

Mother Enrolled in a Job Training Program. As illustrated in Table 2, weighted tabulations show that, in 1990, 39\% of children whose mothers were enrolled in a job training program were enrolled in Head Start, compared with $21 \%$ of other children. This difference is large but not statistically significant in bivariate tabulations. Whether the mother was enrolled in a job training program was, however, significantly related to enrollment of the child in Head Start, after controlling for other factors (Table 3). Children of mothers who were enrolled in a training program wcrc considerably more likely to be enrolled in Head Start than children of mothers not enrolled in such a program. This difference may be due to the mothers' greater knowledge about and access to Head Start through training programs or due to Head Start's better fit with the hours of training (which are often part time).

Income. In simple cross tabulations, eligible children from the lowest income families had no higher likelihood of being enrolled in Head Start than eligible children from the highest income families. More than one quarter of children from families with incomes under $\$ 10,000$ per year were enrolled, compared with 15 to $17 \%$ of those with incomes above $\$ 10,000$, but these differenes were not statistically significant (Table 2). Nor, after controlling for other factors, was income of the family found to be significantly associated with an eligible child's enrollment in Head Start (Table 3). Among eligible families, children from the families with the lowest incomes are about as likely to be enrolled in Head Start as children from families with the highest incomes. This does not imply that programs are not taking needy families. All eligible families are considerably disadvantaged. Our results imply that, 
among families that are eligible, income is apparently not as important as other factors in enrolling a child in Head Start.

Education. The education of the mother matters. Thirty-five percent of children whose mother had less than a high school education were enrolled in Head Start in 1990, compared with an enrollment of $13 \%$ of children whose mother had some college or more (Table 2). There was no difference in enrollment among children of mothers with a high school diploma but no college $(20 \%)$, and children of mothers with more $(13 \%)$ or less $(35 \%)$ education. In the multivariate analysis, net of other factors, each additional year of schooling reduced enrollment in Head Start by a statistically significant $20 \%$ (Table 3). ${ }^{6}$

Race/Ethnicity. Racial differences in enrollment in Head Start appear consistent. The weighted bivariate frequencies show that $30 \%$ of Black and $34 \%$ of Hispanic children were enrolled in Head Start in 1990, compared with $13 \%$ of White children (Table 2). Though both Blacks and Hispanics appear more likely than Whites to be enrolled in Head Start, only the difference between Hispanic and White children was statistically significant in bivariate analyses. However, after adjusting for other differences between these groups, such as income and education, eligible Hispanic children were no longer more likely than White children to be enrolled in Head Start, while eligible Black children were significantly more likely than eligible White children to be enrolled (Table 3).

Regional Differences. Weighted tabulations show that 27 to $28 \%$ of children in the Midwest and the Northeast, and $27 \%$ of children in the West were enrolled in Head Start in 1990, compared with $14 \%$ of children in the South (Table 2). These differences were not statistically significant in bivariate analyses. However, controlling for all the other variables in the multivariate logistic analysis, children in the South were significantly more likely to be enrolled in Head Start than children living in the West, Midwest, and Northeastern U.S. (Table 3).

Urban-Rural Differences. In weighted tabulations, $29 \%$ of eligible children living in a central city were enrolled in Head Start, compared with $11 \%$ of eligible suburban children (Table 2), a difference which is statistically significant. Rural children were neither more nor less likely than central city or suburban children to be so enrolled. However, after controlling for other factors, there were no statistically significant differences in enrollment by whether the child lived in a central city, suburb, or rural area (not shown).

\footnotetext{
- Calculated as (Odds ratio-1)*100. This represents the percentage increase (or decrease) in the adjusted odds of enrolling in Head Start associated with an increase of one unit (e.g., one year of schooling) in the independent variable.
} 
Standard of Living. Surprisingly, controlling for other factors, eligible children living in areas with a higher per capita income had a higher probability of being enrolled in Head Start than those with a lower per capita income (Table 3). A child living in a community with a $\$ 1,000$ greater per capita income than another has a $19 \%$ greater probability of being enrolled in Head Start than a child in the comparison community. Such communities may be better organized to apply for and manage Head Start funds than poorer communities. Targeting funds to poor communities might help to equalize Head Start coverage.

Supply of Early Childhood Programs. In areas with more Head Start programs per 1,000 children, enrollment in Head Start was higher, though the effect is only marginally statistically significant because the estimate is not very precise. In 1990 there was, on average, about 1 Head Start program for every 2,000 preschool children. The supply of other types of centerbased programs was also related to Head Start enrollment. The higher the ratio of child-care centers (other than Head Start) to children, the higher the probability of a child's being enrolled in Head Start, suggesting that such programs complement each other. In contrast, regulated family day care programs may compete with Head Start programs. Net of other factors, the higher the ratio of regulated family day programs to children in the county, the lower the enrollment in Head Start. This effect is significant at the .10 level. A similar relationship held for public school-based programs. That is, the more school-based programs per 1,000 preschool children, the less the enrollment in Head Start, though the coefficient is not statistically significant. These results suggest that public school programs may also compete with Head Start, though more evidence is needed. Public school programs provide some of the same services that Head Start provides (Hofferth and Kisker, in press). Because the supply of other types of center-based programs-child-care centers and nursery schools- is related positively to enrollment in Head Start, this suggests that these center-based programs are complementary to Head Start rather than substitutes for it. They do not, as a rule, provide the same types of services as those provided by Head Start.

\section{THE CHILD CARE ARRANGEMENTS OF NON-HEAD START CHILDREN IN 1990}

Parents of non-Head Start children were asked which arrangement was used the most hours, the next most hours and so on, and arrangements were ordered by the hours the child spent in the arrangement. In analyses examining the combinations of multiple arrangements parents use, the primary arrangement is the one in which the child spent the most time during the week before the survey and the secondary arrangement is the one in which the child spent the next most time. 


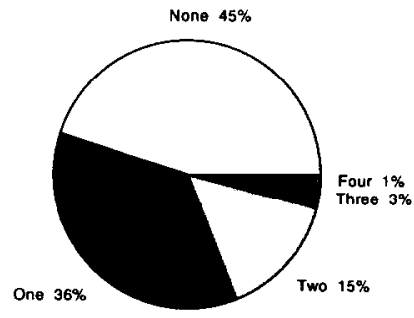

Non-Head Start

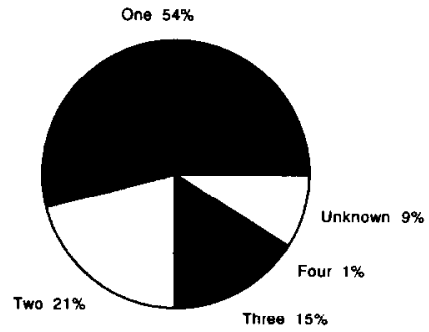

Head Start

Figure 1. Number of Nonparental Arrangements.

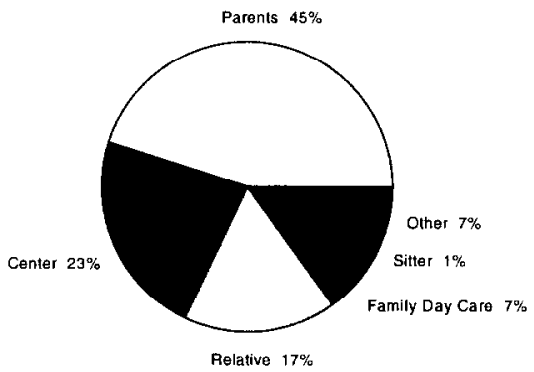

Primary

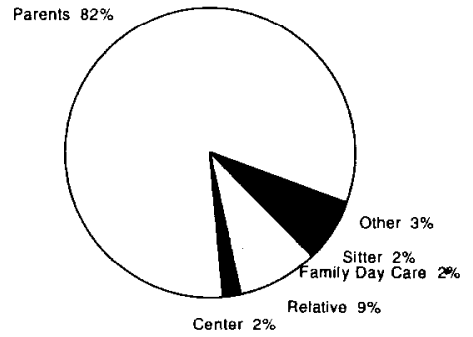

Secondary

Figure 2. Arrangements Used by Non-Head Start Families.

\section{Number of Nonparental Arrangements}

As shown in Figure 1, of children who were not enrolled in Head Start, 55\% had one or more nonparental arrangement in 1990. Forty-five percent had no nonparental arrangement, $36 \%$ had one, and $19 \%$ had two or more arrangements. It appears from these figures that a substantial proportion $(45 \%)$ of potential Head Start enrollees were in parental care rather than other child-care arrangements.

\section{Types of Arrangements Used}

What are the types of arrangements and programs that non-enrolled Head Start-eligible families use?

Primary Arrangement. As shown in Figure 2, parents alone cared for children in $45 \%$ of non-Head Start families in 1990 . As their primary arrangement, $23 \%$ used a center, $17 \%$ a relative, $1 \%$ a sitter in the child's home, $7 \%$ a family day care home provider, and $7 \%$ other arrangements. Thus, at least $23 \%$ of potential Head Start enrollees come from other center-based programs and $7 \%$ come from family day care homes. 


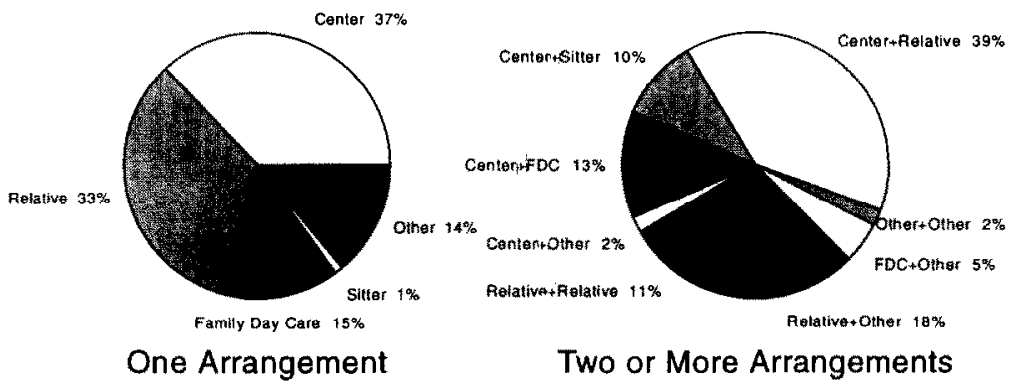

Figure 3. Arrangement Combinations Used by Non-Head Start Families.

Secondary Arrangements. The estimate of non-Head Start families' present use of centers based on the primary arrangement is slightly low, because some families use multiple arrangements. Of the $36 \%$ of non-Head Start families using one arrangement (Figure 1), 37\% used a center in 1990 (Fig. 3). Of the $19 \%$ of non-Head Start families using two or more arrangements (Figure 1), 64\% used a center along with another arrangement (Figure 3). This means that a total of $25 \%$ of non-Head Start families used a center at some point. ${ }^{7}$ Thus, $25 \%$ of potential Head Start recruits were already enrolled in a center.

Of those non-Head Start families using one arrangement, $15 \%$ used a family day care home (Figure 3). Of non-Head Start families using two or more arrangements, $18 \%$ used a family day care home (Figure 3). Using the same type of calculation, 9\% were already enrolled in a family day care home. The remainder were primarily in the care of a relative, in parent care, or in other miscellaneous arrangements. Few were cared for by a sitter in the child's home.

\section{Sponsorship of Non-Head Start Programs}

An important issue is the sponsorship of non-Head Start programs. In what types of center-based programs are non-Head Start children enrolled? Do these programs provide the types of services that Head Start programs provide? Head Start programs almost uniformly provide physical and dental exams; hearing, speech, and vision testing; and psychological, cognitive, and social development testing (Hofferth \& Kisker, in press; Zigler, Piotrkowski, \& Collins, 1994). Parents also participate extensively in Head Start programs (Kisker et al., 1991). As discussed earlier, other programs range from providing somewhat similar services to providing very few.

Non-Head Start children enrolled in center-based programs are enrolled in various types of programs, according to parents' reports. As shown in

${ }^{7}$ This was arrived at by calculating $(.36 \times .37)+(.19 \times .64)=.25$. 


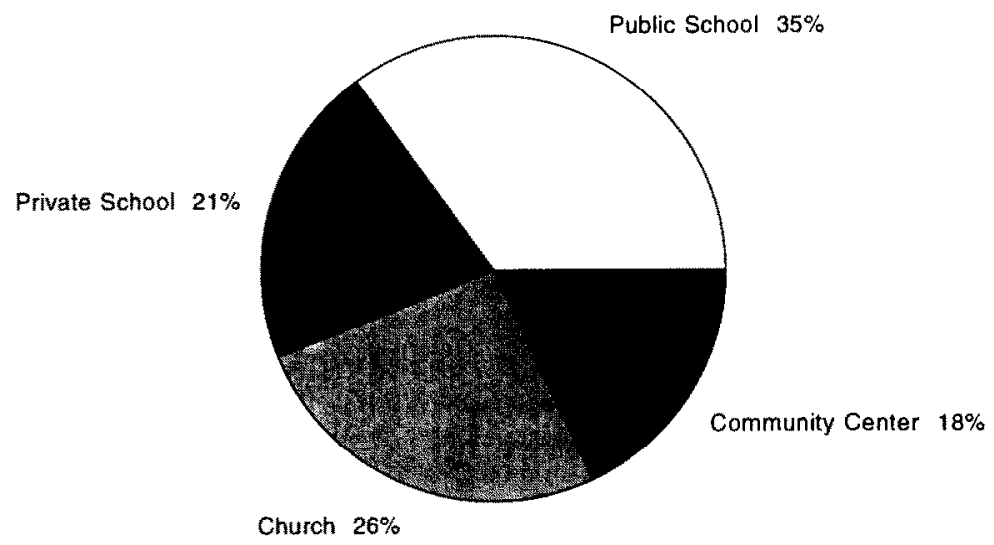

Figure 4. Location of Non-Head Start Children's Center-Based Programs.

Figure 4, in 1990, $56 \%$ were in school-based programs (35\% in public schools, $21 \%$ in private schools), $26 \%$ in church-based programs, and $18 \%$ in programs in community centers. Almost all these programs were sponsored by the organization in the premises of which the center was located, though churches and public schools were least likely ( $85 \%$ and $88 \%$, respectively) to sponsor the programs located there. As discussed earlier, programs in schools provide a variety of services, although they are not as extensive as those of Head Start (Hofferth \& Kisker, in press; Zigler, Piortrkowski \& Collins, 1994). In 1990, three quarters of programs in schools provided cognitive, social development, hearing, speech and vision testing; three fifths provided psychological testing; and one third provided physical and dental exams. Other types of programs were less likely to do so.

\section{FAMILY AND COMMUNITY CHARACTERISTICS RELATED TO HEAD START-ELIGIBLE PARENTS', USE OF MULTIPLE ARRANGEMENTS}

Ordinary least squares multiple regression was used to analyze factors associated with the number of different early childhood programs in which poor 3- to 5-year-old children were enrolled. The same sample of 212 children eligible for Head Start was used.

\section{Who Uses Multiple Arrangements?}

We hypothesized that the use of multiple arrangements would be associated with maternal employment. It is likely that the use of multiple arrangements is stressful and, therefore, used only when necessary due to maternal employment. More arrangements make coordination tricky and stressful 
(Eichman \& Hofferth, 1993) Parents have to find a way to move children from one arrangement to another, unless the arrangements are located within the same building. Consequently, we were interested in examining the factors associated with the number of arrangements Head Start-eligible parents use for their 3- to 5-year-old child in a multivariate model. Since children enrolled in Head Start are, by definition, in at least one arrangement, we controlled for whether a child was enrolled in Head Start. The results are shown in the last column of Table 3.

Children in Head Start were, as expected, in significantly more arrangements than non-Head Start children. For example, children in Head Start families had 1.5 arrangements on average, compared with 1 arrangement for non-Head Start children (not shown).

Net of Head Start, factors such as number of children, family structure and employment, training, and supply of Head Start programs were related to the number of arrangements. For example, large families were much less likely to use multiple child-care arrangements than small families. It is more expensive and difficult to manage multiple arrangements as family size increases. Children in two-parent families and families with a nonemployed single mother were much less likely to be enrolled in multiple arrangements than children of single-employed mothers. The coefficient for two-parent families with mother employed was negative but small and not significant, suggesting that if the mother is the only earner in a two-parent family she may not be able to rely on her husband for child-care assistance. Children of mothers in job training were also more likely to be in multiple arrangements than children of parents who were not in job training.

Finally, children living in counties with a larger number of Head Start or other center-based programs per 1,000 children were more likely to be in multiple arrangements. These relationships are significant at the .10 level. This is consistent with the argument that greater supply leads to greater use of programs. Standard of living (measured by per capita income in county) was not related to number of arrangements.

\section{WHAT ARE THE TYPES OF SUPPLEMENTARY AND \\ “WRAP-AROUND" ARRANGEMENTS USED BY HEAD START AND NON-HEAD START FAMILIES?}

How do the $37 \%$ Head Start families with two or more arrangements (Figure 1) combine Head Start with something else to care for their children? As shown in Figure 5, in 1990, over half $(52 \%)$ of Head Start families with multiple arrangements used a relative to care for their child before or after their Head Start program, 22\% used a sitter in the child's home, $10 \%$ used another center-based program, $4 \%$ used a family day care home, and $8 \%$ had some other kind of arrangement. Those few families 


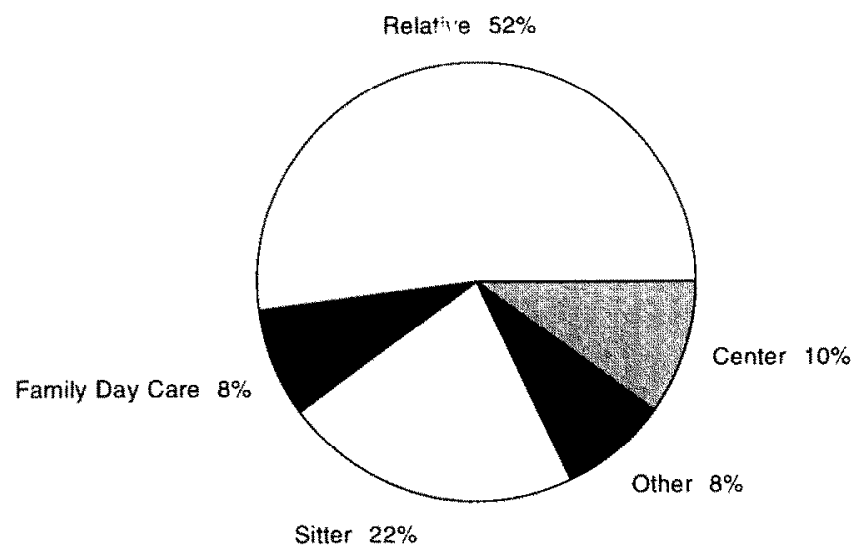

Figure 5. Second Arrangements Used by Head Start Families with Multiple Arrangement

with three or more arrangements usually supplemented the first two arrangements with additional relative care or activities such as lessons.

Of the $19 \%$ of non-Head Start families that used two or more arrangements (Figure 1), 39\% used a center and a relative, $10 \%$ a center and sitter, $13 \%$ a center and family day care, and $2 \%$ used a center and something else (Figure 3). Twenty-nine percent used a relative and something other than a center (such as another relative), 5\% used family day care and something else other than a center or relative, and $2 \%$ used a combination of other arrangements.

\section{DISCUSSION}

Although these data were collected in late 1989 and early 1990, and expansion of Head Start has already begun, we have no reason to believe that the types of people who were enrolled in 1990 differ substantially from those who were enrolled in 1993. Although enrollment levels may have risen overall, no major changes in program services or in the distribution of programs and services among eligible populations have occurred since 1990. Consequently, this analysis can provide useful information to present administrators.

As Head Start expands, many decisions will need to be made regarding the types of services provided and the populations it will increasingly need to serve. The first purpose of this analysis was to identify populations that are currently somewhat underserved, so that recruitment efforts could be concentrated in the areas where these populations are located and the types of services that such populations would need could be defined. The second purpose was to identify whether populations not currently served by Head Start are currently served by other center-based programs that might provide some 
of the same services provided by Head Start. In that case, they would not necessarily need to be enrolled in Head Start. The third purpose was to identify the need for supplemental and wraparound care arrangements that families would need in Head Start. We discuss these three issues as follows.

\section{Underserved Populations}

This analysis provides evidence that Head Start could increase enrollments by better targeting enrollment efforts on children in employed-mother families, whether one or two parents are present. Children in these families were under-enrolled in Head Start in 1990. Yet employed-mother families constituted $25 \%$ of children in non-Head Start families. Whether or not both parents are present, when the mother is employed, additional child-care services are needed, particularly wraparound services. Children in single-parent employed-mother families and children in two-parent families in which the mother only is employed were more likely to use multiple arrangements than other families. Another question is whether such parents would be able to be as actively involved as nonemployed-mother families, and whether accommodation to these parents' schedules would have to be made.

The highest level of Head Start enrollment was found among children in two-parent, neither-employed families. This suggests that two-parent families, in general, have a considerable advantage in enrollment in Head Start, probably because of the greater ease of managing work and family responsibilities when there are two parents than when only one is present. Head Start programs will need to be sensitive to the work as well as family responsibilities of the single parent.

White and Hispanic children were found to be underenrolled in Head Start compared to Black children. Sample sizes were too small to conduct separate analyses of the types of programs in which White, Black, and Hispanic non-Head Start children were enrolled.

Support for the success of job training programs in getting children of participants into Head Start was found. Mothers in a training program were very likely to enroll eligible children in Head Start. More information is needed to determine whether this is because of increased information, increased motivation, or easier scheduling.

\section{Duplication of Services}

Moving children into Head Start is not likely to result in duplication of services or undue harm to their current private providers. The majority of children who were not enrolled in Head Start in 1990 were cared for by their parents or by a close relative. Only about $25 \%$ of such children were in a center-based program as the primary or secondary arrangement. Over half $(56 \%)$ of those non-Head Start children enrolled in center-based programs were in school-based programs, which provide services somewhat similar to, 
though not identical to those provided by Head Start. The other $44 \%$ were in programs located in churches or in community centers, which were less likely to provide such services. Thus, full enrollment in Head Start might consist of enrolling $86 \%$ of children in Head Start, and $14 \%(.25 \times .56)$ in other centerbased programs that provide similar services. In addition, there will be some parents who, for a variety of reason, will not want to enroll their child in a preschool program. How family day care fits into the picture of service delivery to low-income children and their families is an additional question for debate. Some $9 \%$ of non-Head Start children were enrolled in family day care as their primary or secondary child-care arrangement.

\section{Additional Services}

Parents using Head Start were more likely to use multiple programs than parents not using Head Start. The most common combination was relative care with center-based care, both for Head Start and for non-Head Start parents using multiple arrangements. Clearly the cost and convenience of arranging other care is an important consideration, since fewer parents pay relatives and, those who do, pay less than they would pay other providers. Few parents reported using two center-based programs, suggesting that this is not a common practice or that respondents do not consider wraparound center-based programs to be separate arrangements.

\section{Conclusions}

In conclusion, there is evidence that programs will need to provide more services to employed parents as Head Start expands. However, even more critical are services that help single parents to manage their responsibilities. This may include transportation, counseling, and other types of social services as well as wraparound child care programs. There is little evidence that an expanding Head Start would compete with existing center-based preschool programs that provide comprehensive services. Only a small minority (about $14 \%$ ) of non-Head Start children are in such programs. Improving services to non-Head Start center-based programs would help only a small proportion of nonenrolled but eligible Head Start children. Most are in the care of parents and close relatives.

\section{REFERENCES}

Abt Associates. (1990) Final report on survey methods: National Child Care Survey, main study and low-income study. Cambridge, MA: Abt Associates.

Advisory Committee on Head Start Quality and Expansion. (1993). Creating a 21st century Head Start. Washington, DC: U.S. Department of Health and Human Services. 
Besharov, D. (1991). Child care in the 1990s: selected statistics. Washington, DC: American Enterprise Institute for Public Policy Research.

Chafel, J. (1992). Funding I Iead Start: What are the issues? American Journal of OrthoPsychiatry, 62, 9-21.

Collins, R. (1993, November). Family-focused Head Start health services: yesterday, loday and tomorrow. Paper presented at the Head Start National Research Conference, Washington, DC.

Committee on Ways and Means, U.S. House of Representatives. (1994). Overview of entitlement programs. Washington, DC: U.S. Government Printing Office.

Copple, C., Deich, S., Brush, L., \& Hofferth, S. (1993). Learning readiness: Promising strategies. Washington, DC: U.S. Department of Health and Human Services.

Eichman, C., \& Hofferth, S. (1993, April). Family strategies for managing work and family life. Paper presented at the Annual Meeting of the Population Association of America, Cincinnati, $\mathrm{OH}$.

Hofferth, S., Brayfield, A., Deich, S., \& Holcomb, P. (1991). National Child Care Survey 1990. Washington, DC: The Urban Institute.

Hofferth, S. \& Kisker, E. (in press), Comprehensive services in child care settings: prevalence and correlates. Pediatrics.

Kisker, E., Hofferth, S., Phillips, D., \& Farquhar, E. (1991). A profile of child care settings: Early education and care in 1990. Washington, DC: U.S. Government Printing Office.

National Head Start Association. (1989) Testimony before the House of Representatives Committee on Education and Labor, March 6, 1989, presented by Eugenia Boggus, President, NHSA.

National Head Start Association. (1990). Head Start: The nation's pride, a nation's challenge. Alexandria: VA: National Head Start Association.

Rovner, J. (1991). Head Start is one program everyone wants to help. Congressional Quarterly, $48,16,1191-1195$.

Stewart, A. (1993). Head Start: A fact sheet. Washington, DC: Congressional Research Service. U.S. Bureau of the Census. (1994). Statistical abstract of the United States, 1994. Washington, DC: U.S. Government Printing Office.

Zigler, E. \& Muenchow, S. (1992). Head Start: The inside story of America's most successfut educational experiment. New York: Basic Books.

Zigler, E., Piotrkowski, C., \& Collins, R. (1994). Health services in Head Start. Annual Review of Public Health, 15, 511-534.

\section{APPENDIX: DATA QUALITY}

\section{Evaluation of NCCS Data on Low-Income Children}

Analysis of the NCCS shows that $23 \%$ of 3- to 4-year-old children and 5 -year-olds not enrolled in school whose families were poor or receiving AFDC were enrolled in Head Start in 1990. How does this compare to the percentage of children in all eligible families who were enrolled in Head Start in 1990 based on official sources? The NCCS figures were compared with estimates of the proportion of poor children enrolled in Head Start that were calculated from CPS data (Besharov, 1991). The comparison was made assuming that all children in families below the poverty line were eligible for Head Start and that only $5 \%$ of families above the poverty line were eligible. The NCCS figures were also compared to estimates for 1992 prepared by Ann Stewart (1993) of the Congressional Research Service. The 
NCCS data were collected in fall 1989 , winter, and spring 1990 . This timespan is apparently comparable to the ACYF 1990 fiscal year. ACYF estimated enrollments of 540,000 children in Head Start in 1990; the NCCS estimate was a total of 583,734 , of whom 463,000 were contained in our eligible population. If $10 \%$ of Head Start enrollees can be over income, that implies that the NCCS estimate based on eligible populations should be $463,000+46,000$, or 509,000 children. The estimated enrollment of 583,000 in the NCCS implies that about $20 \%$ are over-income eligibility. Taking the ACYF figures as correct and the NCCS numbers as too high yields an overincome eligibility rate of $14 \%$.

The NCCS 1990 estimate of the proportion of poor 4-year-old children enrolled in Head Start (32\%, including single father and no parent families) was similar to that obtained for 1989 from CPS data (34.2\%) and lower than the estimate for 1990 (40.6\%) (Besharov, 1991) — but within the large $95 \%$ confidence interval ( + or -13 percentage points) due to small sample sizes. The Congressional Research Service (CRS) figures for 4-year-olds for 1992 was also $40 \%$ (Stewart, 1993). On the other hand, the NCCS estimate of coverage for 5 -year-olds $(24 \%)$ is considerably larger than the estimate from the CRS ( $16 \%)$ based on similar assumptions, and smaller for 3-yearolds (10 compared with $16 \%$ ).

There are several plausible reasons for these discrepancies:

- Parental misreporting of their child's Head Start status. High-income parents may report their child as being enrolled in Head Start when he or she is in a related or co-located program.

- The NCCS and CPS use household income in their calculation of poverty status. However, the Head Start program may use the family unit as the unit for eligibility. Thus a subfamily (e.g., teen parent living with her mother) may be eligible, whereas if the income of her entire household were counted it would put the household considerably above the poverty line.

- Parents may be inaccurately reporting their incomes to Head Start grantees determining program eligibility. They may report only their own incomes and not that of others in their families. They may say they do not work when actually they do, and so on.

- Eligibility is determined only once, and family income changes over time. Consequently, some of those once eligible may no longer be, especially those interviewed in the spring or in their second year of Head Start.

- The NCCS underestimates coverage at age 4 and overestimates it for 5-year-olds relative to the CPS. The ACYF determines age at eligibility in the fall when children are 4, but children are enrolled for one to two years. A cross-sectional survey obtained the following winter and spring 
should obtain a higher count of 5-year-olds and a lower count of 4-year-olds as children age from fall to spring. This is supported by NCCS data on the distribution of Head Start children by age. The NCCS shows $21 \%$ of Head Start children to be age 3,66\% age 4, and $13 \%$ age 5 . ACYF figures show $3 \%$ under age $3,25 \%$ age $3,64 \%$ age 4 , and $8 \%$ age 5 . The small differences at ages 3 and 5 are consistent with the difference between determining age at eligibility and at a point in time in a survey.

- Finally, the coverage estimates based upon CPS data are just that, estimates. The numbers depend on the assumptions that underlie eligibility. These assumptions are impossible to verify.

\section{Improvements in Data Quality}

In order to improve the quality of the data, Urban Institute staff examined the sample of Head Start families to see whether some of the nonpoor families contained subfamilies that might be eligible, and compared Head Start enrollment rates in poor families with and without subfamilies.

Some of the discrepancy can be explained by the difference between household and family income. By including only those families that do not have a secondary family in the same household, the proportion of poor 4-year-old children enrolled in Head Start rose from 32 to $34 \%$. The NCCS then reproduced the CPS enrollment rate of $34 \%$ for 1989 , but this is still lower than the $40.6 \%$ estimated enrollment rate for 1990 .

The reader should note that the data in the present report have been reweighted to adjust for underrepresentation of poor children in the original NCCS. Although reweighting the sample increases the size of the population that is poor and increases Head Start enrollments of 4-year-olds by about $10 \%$, bringing it close to other estimates of coverage, it does not completely eliminate the percentage over income in the NCCS, according to ACYF eligibility rules.

\section{Implications for the Present Study}

To the extent that poor children are underrepresented in the NCCS (see Hofferth et al., 1991, Appendix B) and that very low-income children's child-care arrangements are more likely to be informal, we may be slightly overestimating the proportion of formal arrangements and underestimating the incidence of informal arrangements. Among the subsample of poor families, reweighting increased enrollments by a small but insignificant amount. 